\title{
LONG SPAN BRIDGE DESIGN TREATED WITH UHPC IMPLEMENTATION
}

\author{
Naveenkumar Swamy \\ Department of Civil Engineering \\ University of Bologna, Bologna, Italy, Tongji University, Shanghai, China
}

\begin{abstract}
In the last several years great progression has been created in the investigation and development of a brand-new kind of concrete called ultra-high-performance concrete (UHPC). This high-tech material has excellent material attributes as compared to traditional concrete and has the potential to create slender and lighter structures. Nevertheless, the content is still really costly and requires designers to reduce material use to make an economic structure. The application of UHPC is able to enhance the box shaped cross section in a number of ways. Very slender beams could be created by using a higher amount of prestress. Also, wider beams with very slim webs can be made because of the high shear capacity. For this particular master thesis 5 different kinds of UHPC box beams are actually developed. These optimized box beams are actually created for bridges spanning $60 \mathrm{~m}, 80 \mathrm{~m}$, $70 \mathrm{~m}, 85 \mathrm{~m}$ and $90 \mathrm{~m}$. The most crucial benefits of these UHPC box beams over box beams made of standard concrete are:
\end{abstract}

- $\quad$ The beams are actually slenderer

- The beams are actually wider: o Less beams must be produced, transported and assembled, lessening the amount of time and labor necessary to construct the bridge.

- $\quad$ The beams are actually lighter: o the total loading of the bridge is actually reduced by the lower self-weight. o They're easier in order to transport as well as to hoist. o Longer beams up to $90 \mathrm{~m}$ may be made without exceeding the 170t weight limit for transport by road.

These benefits enable the UHPC box beams to be a fit solution for spans which are way too long for conventional box beam strategies, without having to create an intermediate pier or even to shift to segmented or even cast in situ solutions. Additionally, they are able to change old bridges with a stronger one without having to change the substructure. Consequently, it could be concluded that UHPC beams provide build brand new bridges and replace older bridges with little traffic hindrance.

\section{INTRODUCTION}

The Increasing demand of highways. Additionally, many existing bridges reach their service life and/or don't have the capability to carry the improved traffic intensities and many of them may have to be replaced or perhaps strengthened. When a new bridge must cross a highway with higher traffic intensity, there's usually a need for a bridge which may be constructed with minimum traffic hindrance. The exact same holds for old bridges that should be changed. It's ideal that these may be replaced with minimum traffic hindrance. By taking away the demand for an intermediate pier the traffic hindrance can be cut down considerably. Nevertheless, at the exact same time the span increases with a significant amount. Therefore, to minimize traffic hindrance, road bridges that can easily span longer distances are actually needed. Furthermore, it's also appealing that when a bridge is actually replaced, the current substructure would still have the ability to withstand the increased traffic loading. This could just be accomplished if the replacing superstructure is substantially lighter.

\section{PROBLEM DESCRIPTION}

In the previous years a new information, referred to as UltraHigh-Performance Concrete (UHPC), is actually being created and has shown results that are promising in the two tests and in training. This substance which is characterized by extremely substantial compressive toughness, shear capacity and advantageous cracking conduct, has the possibility to make extremely durable bridges which have the chance to span long distances with no intermediate piers. Additionally, these bridges may additionally be substantially lighter. Thus, this content appears to be the perfect choice to be used in road bridges that will need minimum site traffic hindrance during building. Nevertheless, the high expenses of the content, which is much more than 8 times the expense of typical concrete, poses a major struggle for the custom of the bridge. To make an economic style, the material use must be held to a bare minimum. This may be accomplished by locating a structural idea which uses the excellent information qualities of UHPC almost as possibleDWT Decomposition model. 


\section{International Journal of Engineering Applied Sciences and Technology, 2020 \\ Vol. 5, Issue 6, ISSN No. 2455-2143, Pages 19-26 \\ Published Online October 2020 in IJEAST (http://www.ijeast.com)}

\section{OBJECTIVES OF RESEARCH}

The goal of this article is actually finding an economic look for UHPC in span that is long $(\geq 60 \mathrm{~m})$ street bridges. design concepts that are Different will be examined to find the one that's most appropriate. This idea will be enhanced and eventually a look of an enhanced UHPC bridge is going to be offered.

\section{BRIDGE PROPERTIES}

To figure out when it is better to put on UHPC and how you can use it to the fullest potential of its, a great comprehension of the material as well as its action is actually needed. Consequently, in this particular chapter the mechanical and physical properties of UHPC are actually summarized. To be able to have the ability to design with the content, recommendations regarding distinctive and design values are usually provided. These're taken using the Recommendations on Ultra High-Performance Fiber Reinforced Concretes created by the AFGC. This's generally the French style code for UHPC

\begin{tabular}{|l|l|l|l|}
\hline Density & $\rho$ & 2.500 & $\mathrm{~kg} / \mathrm{m}^{3}$ \\
\hline Characteristic compressive strength & $\mathrm{f}_{\mathrm{ck}}$ & 150 & $\mathrm{~N} / \mathrm{mm}^{2}$ \\
\hline Characteristic elastic tensile strength & $\mathrm{f}_{\mathrm{ctk}, \mathrm{el}}$ & 9 & $\mathrm{~N} / \mathrm{mm}^{2}$ \\
\hline Characteristic post-cracking tensile strength & $\mathrm{f}_{\mathrm{ct} f \mathrm{k}}$ & 9 & $\mathrm{~N} / \mathrm{mm}^{2}$ \\
\hline Mean modulus of elasticity & $\mathrm{E}_{\mathrm{cm}}$ & 50.000 & $\mathrm{~N} / \mathrm{mm}^{2}$ \\
\hline Fiber orientation factor for global effects & $\mathrm{K}_{\mathrm{global}}$ & 1,25 & - \\
\hline Fiber orientation factor for local effects & $\mathrm{K}_{\text {local }}$ & 1,75 & - \\
\hline Material factor UHPC & $\gamma_{\mathrm{c}}$ & 1,5 & - \\
\hline Shrinkage - heat treatment hardened concrete & $\varepsilon_{\mathrm{cs}, \mathrm{hht}}$ & 550 & $\mu \mathrm{m} / \mathrm{m}$ \\
\hline Shrinkage - heat treatment during curing & $\varepsilon_{\mathrm{cs}, \mathrm{cht}}$ & 550 & $\mu \mathrm{m} / \mathrm{m}$ \\
\hline Shrinkage - no heat treatment & $\varepsilon_{\mathrm{cs}, \mathrm{nht}}$ & 700 & $\mu \mathrm{m} / \mathrm{m}$ \\
\hline Creep factor heat treatment hardened concrete & $\Phi_{\text {hht }}$ & 0,2 & - \\
\hline Creep factor heat treatment during curing & $\Phi_{\mathrm{cht}}$ & 0,4 & - \\
\hline Creep factor no heat treatment & $\Phi_{\text {nht }}$ & 0,8 & - \\
\hline
\end{tabular}

V. UHPC PROPERTIES

\begin{tabular}{|c|c|c|}
\hline Material & $\mathrm{lbs}_{\mathrm{yd}}{ }^{3}$ & $\%$ by wt. \\
\hline Portland Cement $(15 \mu \mathrm{m})$ & 1200 & 28.7 \\
\hline Silica Fume $(\sim 1 \mu \mathrm{m})$ & 390 & 9.3 \\
\hline Quartz Flour $(10 \mu \mathrm{m})$ & 355 & 8.4 \\
\hline Sand $(150$ to $600 \mu \mathrm{m})$ & 1720 & 40.8 \\
\hline Steel Fibers $\left(0.5^{\prime \prime}\right.$ long, $\left.8 \mathrm{~mm} \emptyset\right)$ & 263 & 6.2 \\
\hline High-Range Water Reducer & 51.8 & 1.2 \\
\hline Accelerator/Corrosion Inhibitor & 50.5 & 1.2 \\
\hline Water & 184 & 4.4 \\
\hline
\end{tabular}

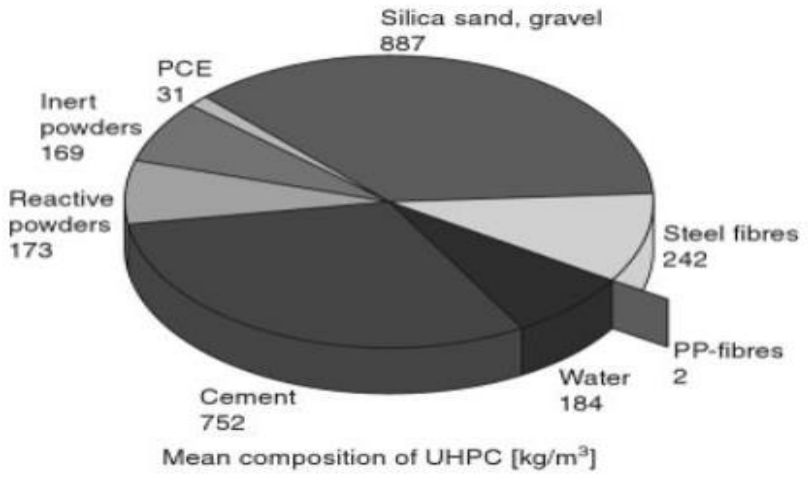

VI. UHPC BEAM BRIDGE DESIGN(>60M)

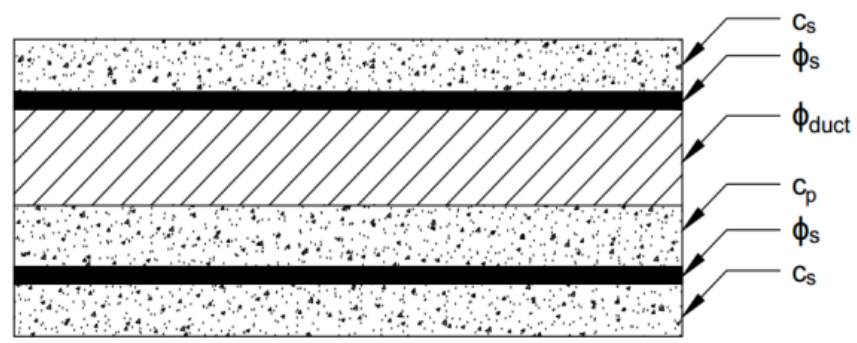

Figure $1 \mathrm{c} / \mathrm{s}$ of top flanges

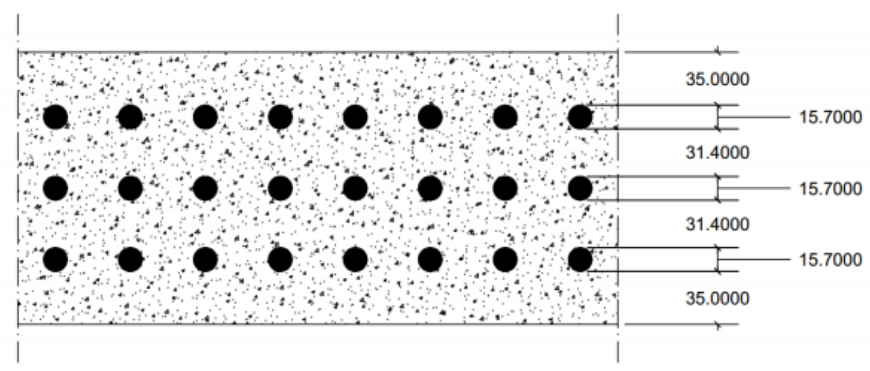

Figure 2 c/s of bottom flanges

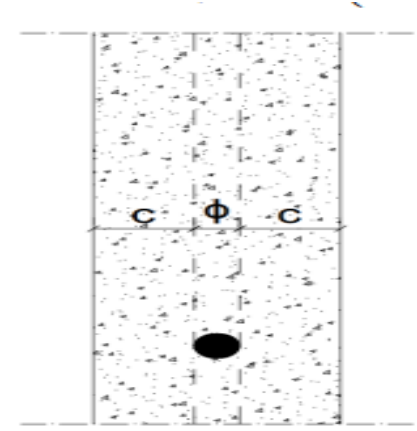

Figure $3 \mathrm{c} / \mathrm{s}$ of web 


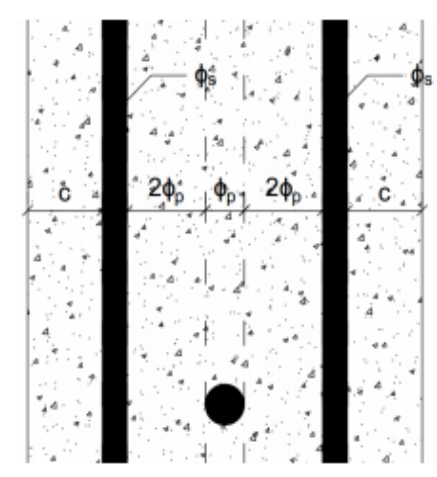

Figure $4 \mathrm{c} / \mathrm{s}$ of web with stirrup installed

\begin{tabular}{|l|l|r|r|l|}
\hline Height & $\mathrm{h}$ & & 1300 & $\mathrm{~mm}$ \\
\hline Width & $\mathrm{b}$ & 1500 & $\mathrm{~mm}$ \\
\hline Top flange thickness & $\mathrm{d}_{\text {top }}$ & 170 & $\mathrm{~mm}$ \\
\hline Bottom flange thickness & $\mathrm{d}_{\text {bot }}$ & 225 & $\mathrm{~mm}$ \\
\hline Web thickness & $\mathrm{d}_{\mathrm{w}}$ & 90 & $\mathrm{~mm}$ \\
\hline Cross-section area & $\mathrm{A}_{\mathrm{c}}$ & & 693 & $\mathrm{~mm}$ \\
\hline $\begin{array}{l}\text { Top fiber distance to neutral } \\
\text { axis }\end{array}$ & $\mathrm{z}_{\mathrm{t}}$ & 607 & $\mathrm{~mm}$ \\
\hline $\begin{array}{l}\text { Bottom fiber distance to } \\
\text { neutral axis }\end{array}$ & $\mathrm{z}_{\mathrm{b}}$ & & $1,908 \times 10^{11}$ & $\mathrm{~mm}^{4}$ \\
\hline Moment of inertia & $\mathrm{I}_{\mathrm{c}}$ & & $2,75 \times 10^{8}$ & $\mathrm{~mm}^{3}$ \\
\hline Section modulus top fiber & $\mathrm{W}_{\mathrm{t}}$ & & $15 \times 10^{8}$ & $\mathrm{~mm}^{3}$ \\
\hline Section modulus bottom fiber & $\mathrm{W}_{\mathrm{b}}$ & & 156000 & $\mathrm{~mm}^{2}$ \\
\hline Amount of prestressing steel & $\mathrm{A}_{\mathrm{p}}$ & & 493 & $\mathrm{~mm}^{6}$ \\
\hline Drape of prestressing strands & $\mathrm{f}_{\mathrm{p}}$ & & 115,5 & $\mathrm{t}$ \\
\hline Mass & $\mathrm{G}$ & & & \\
\hline
\end{tabular}

Figure 5 Properties of 60m Box Beam

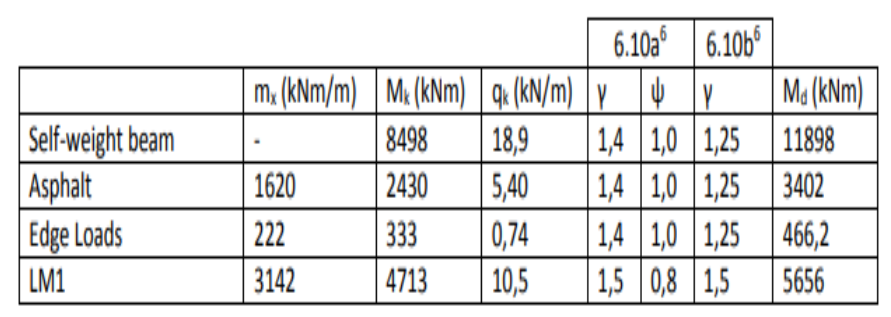

Figure 6 Permanent and Variable Loads

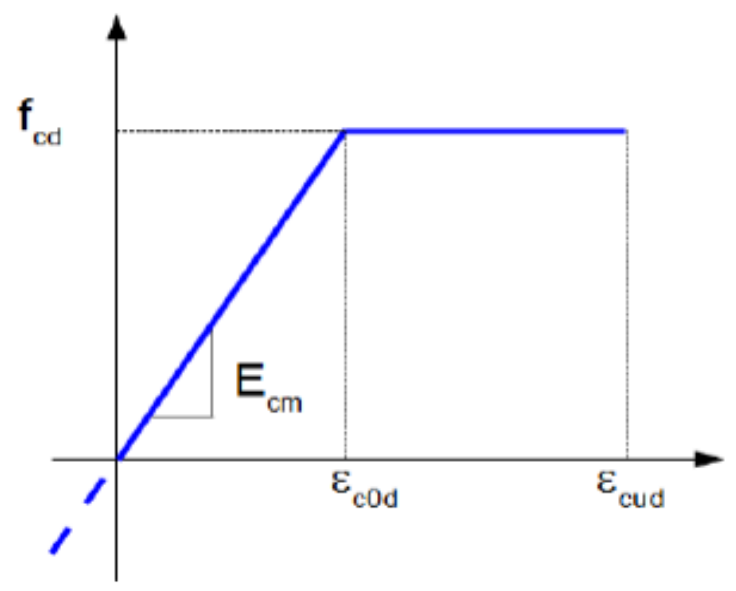

Figure 7 Compressive Stress - Strain Curve

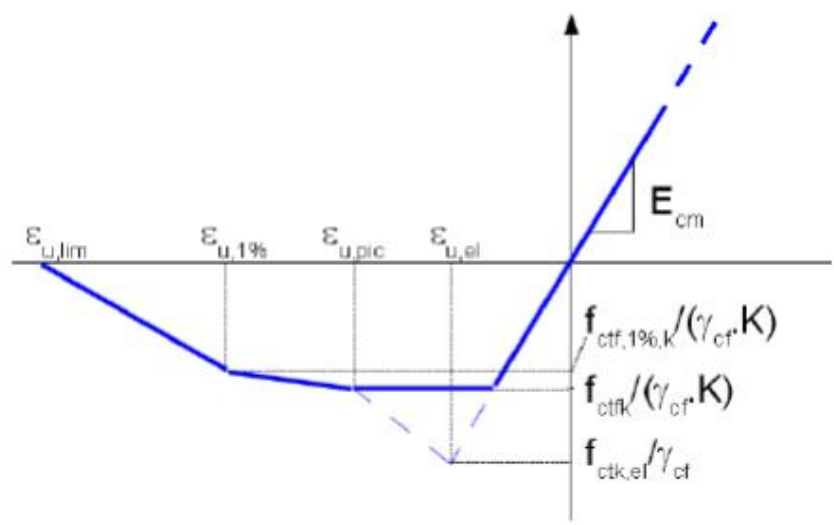

Figure 8 Stress - Strain Curve of Tensile Force

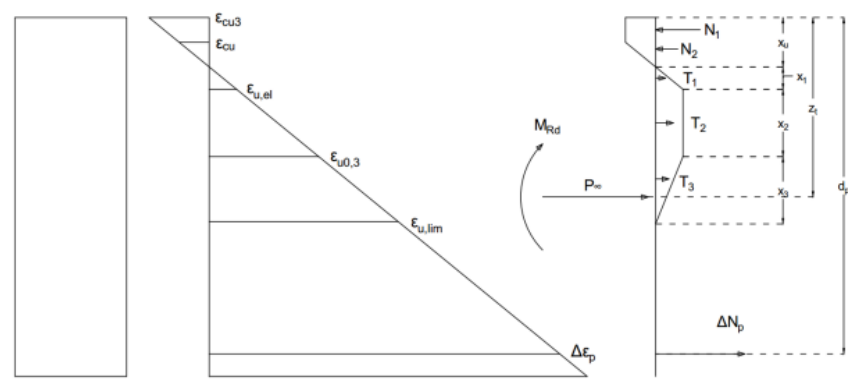

Figure 9 Bending Moment Capacity of Internal Forces

\begin{tabular}{|l|r|}
\hline Moment & 0,66 \\
\hline Shear & 0,97 \\
\hline Transverse moment top flange (cracking) & 0,44 \\
\hline Transverse moment web (cracking) & 0,84 \\
\hline Deflection (traffic) & 0,34 \\
\hline Deflection (camber) & 0,16 \\
\hline Cracking & 0,46 \\
\hline Concrete fatigue & 0,28 \\
\hline Steel fatigue & 0,10 \\
\hline
\end{tabular}

Figure 10 Unity Check Performed For 60m Long Box Beam

VII. UHPC BOX BEAM $(>70 \mathrm{M})$ 
International Journal of Engineering Applied Sciences and Technology, 2020

Vol. 5, Issue 6, ISSN No. 2455-2143, Pages 19-26

Published Online October 2020 in IJEAST (http://www.ijeast.com)

\begin{tabular}{|l|l|r|l|}
\hline Height & h & 1600 & $\mathrm{~mm}$ \\
\hline Width & $\mathrm{b}$ & 1500 & $\mathrm{~mm}$ \\
\hline Top flange thickness & $\mathrm{d}_{\text {top }}$ & 170 & $\mathrm{~mm}$ \\
\hline Bottom flange thickness & $\mathrm{d}_{\text {bot }}$ & 225 & $\mathrm{~mm}$ \\
\hline Web thickness & $\mathrm{d}_{\mathrm{w}}$ & 85 & $\mathrm{~mm}$ \\
\hline Cross-section area & $\mathrm{A}_{\mathrm{c}}$ & $0,797 \times 10^{6}$ & $\mathrm{~mm}^{2}$ \\
\hline Top fiber distance to neutral axis & $\mathrm{Z}_{\mathrm{t}}$ & 855 & $\mathrm{~mm}$ \\
\hline Bottom fiber distance to neutral axis & $\mathrm{Z}_{\mathrm{b}}$ & 745 & $\mathrm{~mm}$ \\
\hline Moment of inertia & $\mathrm{I}_{\mathrm{c}}$ & $3,144 \times 10^{11}$ & $\mathrm{~mm}^{4}$ \\
\hline Section modulus top fiber & $\mathrm{W}_{\mathrm{t}}$ & $3,68 \times 10^{8}$ & $\mathrm{~mm}^{3}$ \\
\hline Section modulus bottom fiber & $\mathrm{W}_{\mathrm{b}}$ & $4,22 \times 10^{8}$ & $\mathrm{~mm}^{3}$ \\
\hline Amount of prestressing steel & $\mathrm{A}_{\mathrm{p}}$ & 174000 & $\mathrm{~mm}^{2}$ \\
\hline Drape of prestressing strands & $\mathrm{f}_{\mathrm{p}}$ & 631 & $\mathrm{~mm}$ \\
\hline Mass & $\mathrm{G}$ & 142,2 & $\mathrm{t}$ \\
\hline
\end{tabular}

Figure 13 Properties of Box Beam (>70m)

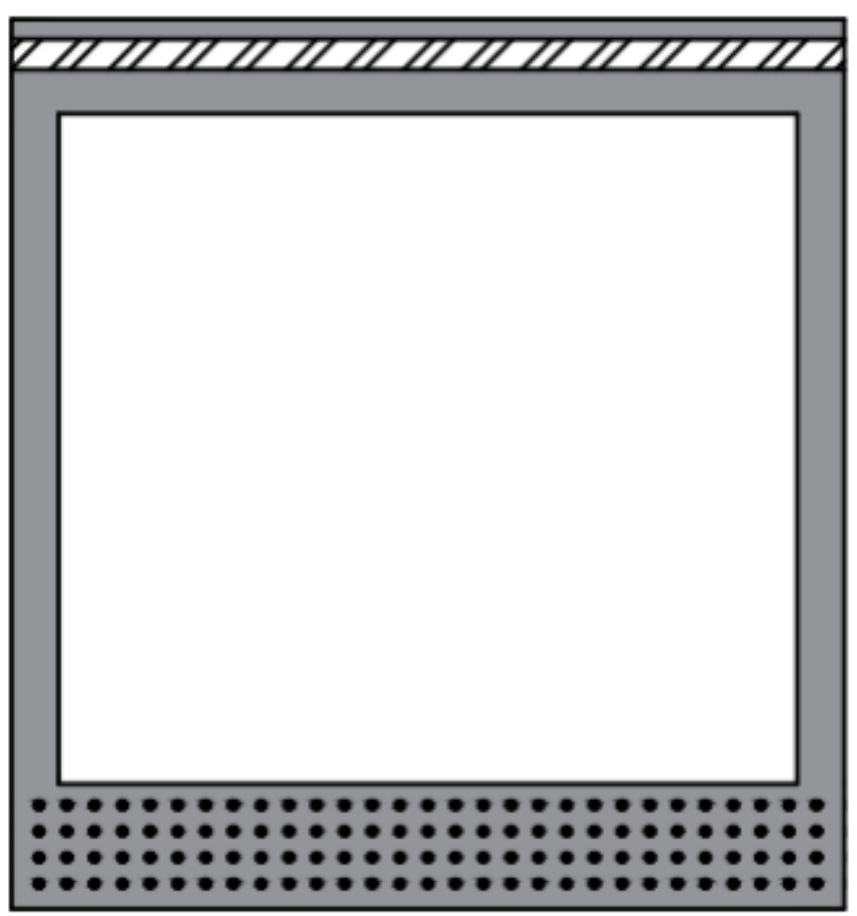

Figure $22 \mathrm{c} / \mathrm{s}$ of transverse post tensioning and pre tensioning

\begin{tabular}{|l|l|}
\hline Moment & 0,58 \\
\hline Shear & 0,95 \\
\hline Transverse moment top flange (cracking) & 0,47 \\
\hline Transverse moment web (cracking) & 0,74 \\
\hline Deflection (traffic) & 0,31 \\
\hline Deflection (camber) & 0,17 \\
\hline Cracking & 0,43 \\
\hline Concrete fatigue & 0,42 \\
\hline Steel fatigue & 0,17 \\
\hline
\end{tabular}

Figure 11 Unity Check Performed on 70m Box Beam
VIII. UHPC BOX BEAM (>80M)

\begin{tabular}{|l|l|r|l|}
\hline Height & $\mathrm{h}$ & 2000 & $\mathrm{~mm}$ \\
\hline Width & $\mathrm{b}$ & 1250 & $\mathrm{~mm}$ \\
\hline Top flange thickness & $\mathrm{d}_{\text {top }}$ & 170 & $\mathrm{~mm}$ \\
\hline Bottom flange thickness & $\mathrm{d}_{\text {bot }}$ & 225 & $\mathrm{~mm}$ \\
\hline Web thickness & $\mathrm{d}_{\mathrm{w}}$ & 85 & $\mathrm{~mm}$ \\
\hline Cross-section area & $\mathrm{A}_{\mathrm{c}}$ & $0,77 \times 10^{6}$ & $\mathrm{~mm}^{2}$ \\
\hline Top fiber distance to neutral axis & $\mathrm{z}_{\mathrm{t}}$ & 1062 & $\mathrm{~mm}$ \\
\hline Bottom fiber distance to neutral axis & $\mathrm{z}_{\mathrm{b}}$ & 938 & $\mathrm{~mm}$ \\
\hline Moment of inertia & $\mathrm{I}_{\mathrm{c}}$ & $4,570 \times 10^{11}$ & $\mathrm{~mm}^{4}$ \\
\hline Section modulus top fiber & $\mathrm{W}_{\mathrm{t}}$ & $4,30 \times 10^{8}$ & $\mathrm{~mm}^{3}$ \\
\hline Section modulus bottom fiber & $\mathrm{W}_{\mathrm{b}}$ & $4,87 \times 10^{8}$ & $\mathrm{~mm}^{3}$ \\
\hline Amount of prestressing steel & $\mathrm{A}_{\mathrm{p}}$ & 180000 & $\mathrm{~mm}^{2}$ \\
\hline Drape of prestressing strands & $\mathrm{f}_{\mathrm{p}}$ & 824 & $\mathrm{~mm}$ \\
\hline Mass & $\mathrm{G}$ & 156,3 & $\mathrm{t}$ \\
\hline
\end{tabular}

Figure 14 Properties of Box Beam(>80m)

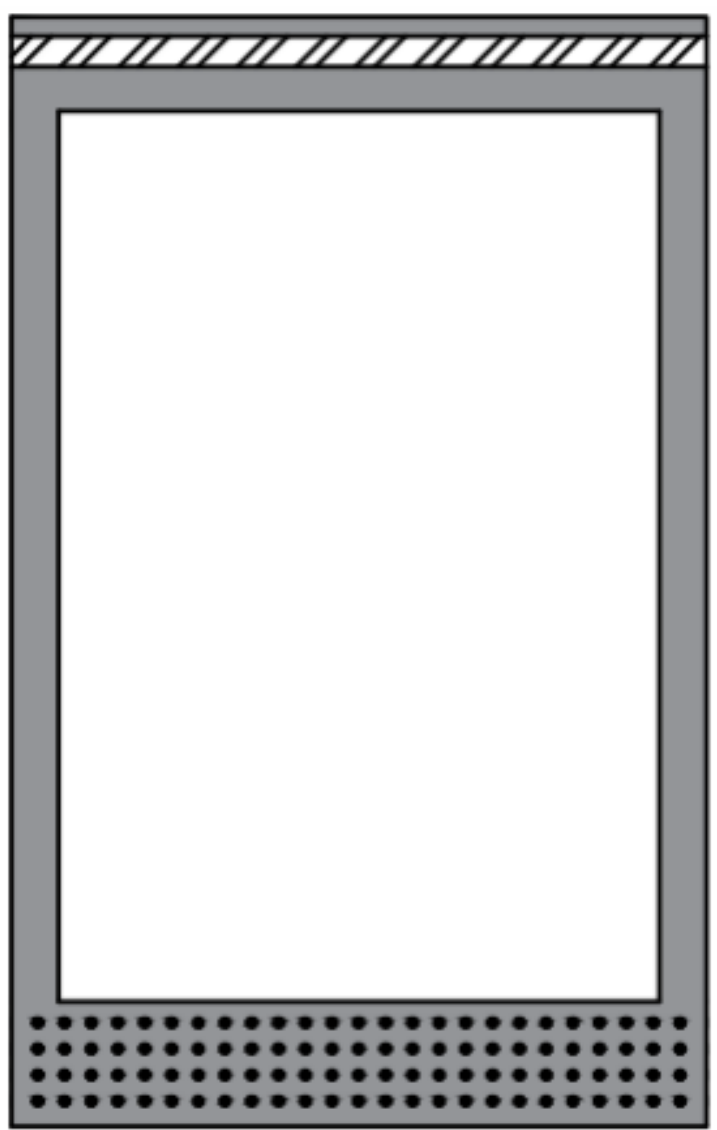

Figure 15 C/s of Transverse Post and PreTensioning 
International Journal of Engineering Applied Sciences and Technology, 2020

Vol. 5, Issue 6, ISSN No. 2455-2143, Pages 19-26

Published Online October 2020 in IJEAST (http://www.ijeast.com)

\begin{tabular}{|l|l|}
\hline Moment & 0,64 \\
\hline Shear & 0,74 \\
\hline Transverse moment top flange (cracking) & 0,41 \\
\hline Transverse moment web (cracking) & 0,46 \\
\hline Deflection (traffic) & 0,23 \\
\hline Deflection (camber) & 0,28 \\
\hline Cracking & 0,50 \\
\hline Concrete fatigue & 0,04 \\
\hline Steel fatigue & 0,22 \\
\hline
\end{tabular}

Figure 17 Unity Check Performed on 80m Long Box Beam

IX. UHPC BOX BEAM $(>85 \mathrm{M})$

\begin{tabular}{|l|l|r|l|}
\hline Height & h & 2200 & $\mathrm{~mm}$ \\
\hline Width & $\mathrm{b}$ & 1000 & $\mathrm{~mm}$ \\
\hline Top flange thickness & $\mathrm{d}_{\text {top }}$ & 170 & $\mathrm{~mm}$ \\
\hline Bottom flange thickness & $\mathrm{d}_{\text {bot }}$ & 270 & $\mathrm{~mm}$ \\
\hline Web thickness & $\mathrm{d}_{\mathrm{w}}$ & 85 & $\mathrm{~mm}$ \\
\hline Cross-section area & $\mathrm{A}_{\mathrm{c}}$ & $0,74 \times 10^{6}$ & $\mathrm{~mm}^{2}$ \\
\hline Top fiber distance to neutral axis & $\mathrm{Z}_{\mathrm{t}}$ & 1199 & $\mathrm{~mm}$ \\
\hline Bottom fiber distance to neutral axis & $\mathrm{z}_{\mathrm{b}}$ & 1001 & $\mathrm{~mm}$ \\
\hline Moment of inertia & $\mathrm{I}_{\mathrm{c}}$ & $4,99 \times 10^{11}$ & $\mathrm{~mm}^{4}$ \\
\hline Section modulus top fiber & $\mathrm{W}_{\mathrm{t}}$ & $4,17 \times 10^{8}$ & $\mathrm{~mm}^{3}$ \\
\hline Section modulus bottom fiber & $\mathrm{W}_{\mathrm{b}}$ & $4,99 \times 10^{8}$ & $\mathrm{~mm}^{3}$ \\
\hline Amount of prestressing steel & $\mathrm{A}_{\mathrm{p}}$ & 225000 & $\mathrm{~mm}^{2}$ \\
\hline Drape of prestressing strands & $\mathrm{f}_{\mathrm{p}}$ & 864 & $\mathrm{~mm}^{\mathrm{m}}$ \\
\hline Mass & $\mathrm{G}$ & 160,1 & $\mathrm{t}$ \\
\hline
\end{tabular}

Figure 18 Properties Of 80m Long Box Beam

\begin{tabular}{|l|l|}
\hline Moment & 0,57 \\
\hline Shear & 0,61 \\
\hline Transverse moment top flange (cracking) & 0,33 \\
\hline Transverse moment web (cracking) & 0,30 \\
\hline Deflection (traffic) & 0,22 \\
\hline Deflection (camber) & 0,34 \\
\hline Cracking & 0,45 \\
\hline Concretef fatigue & 0,15 \\
\hline Steel fatigue & 0,22 \\
\hline
\end{tabular}

Figure18 Unity Check Performed On 85m Long Box Beam

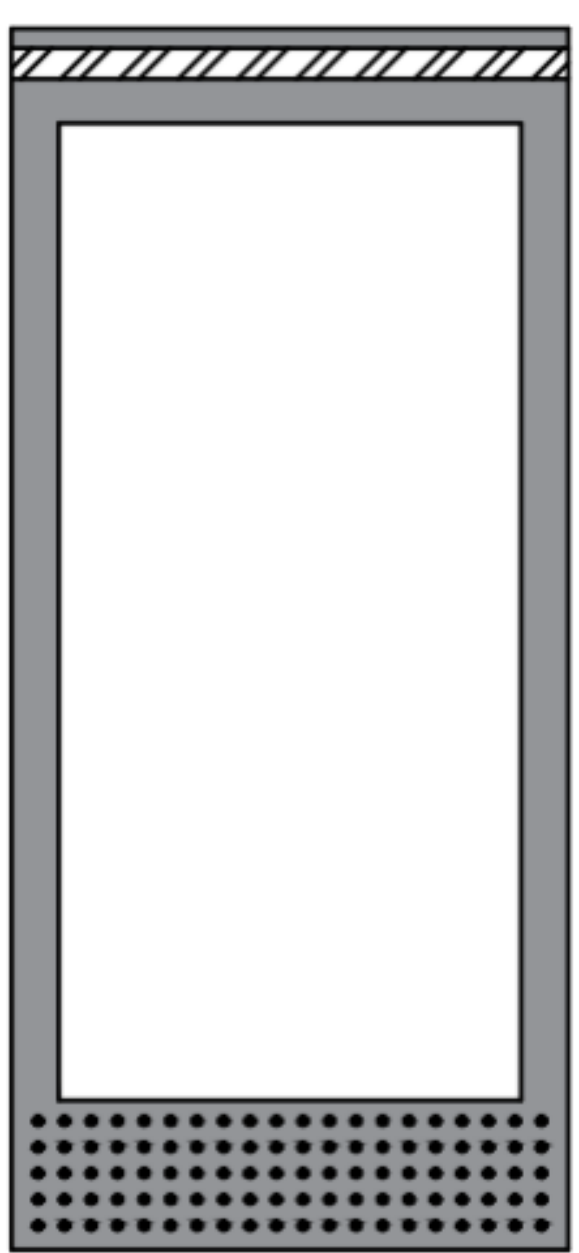

Figure 6 C/s of Transverse Post and PreTensioning

\section{UHPC BOX BEAM $(>90 \mathrm{M})$}

\begin{tabular}{|l|l|r|l|}
\hline Height & $\mathrm{h}$ & 2450 & $\mathrm{~mm}$ \\
\hline Width & $\mathrm{b}$ & 1000 & $\mathrm{~mm}$ \\
\hline Top flange thickness & $\mathrm{d}_{\text {top }}$ & 170 & $\mathrm{~mm}$ \\
\hline Bottom flange thickness & $\mathrm{d}_{\text {bot }}$ & 270 & $\mathrm{~mm}$ \\
\hline Web thickness & $\mathrm{d}_{\mathrm{w}}$ & 85 & $\mathrm{~mm}$ \\
\hline Cross-section area & $\mathrm{A}_{\mathrm{c}}$ & $0,78 \times 10^{6}$ & $\mathrm{~mm}^{2}$ \\
\hline Top fiber distance to neutral axis & $\mathrm{z}_{\mathrm{t}}$ & 1332 & $\mathrm{~mm}$ \\
\hline Bottom fiber distance to neutral axis & $\mathrm{z}_{\mathrm{b}}$ & 1118 & $\mathrm{~mm}$ \\
\hline Moment of inertia & $\mathrm{I}_{\mathrm{c}}$ & $6,51 \times 10^{11}$ & $\mathrm{~mm}^{4}$ \\
\hline Section modulus top fiber & $\mathrm{W}_{\mathrm{t}}$ & $4,89 \times 10^{8}$ & $\mathrm{~mm}^{3}$ \\
\hline Section modulus bottom fiber & $\mathrm{W}_{\mathrm{b}}$ & $5,82 \times 10^{8}$ & $\mathrm{~mm}^{3}$ \\
\hline Amount of prestressing steel & $\mathrm{A}_{\mathrm{p}}$ & 225000 & $\mathrm{~mm}^{2}$ \\
\hline Drape of prestressing strands & $\mathrm{f}_{\mathrm{p}}$ & 981 & $\mathrm{~mm}^{2}$ \\
\hline Mass & $\mathrm{G}$ & 179,3 & $\mathrm{t}$ \\
\hline
\end{tabular}

Figure 20 Properties of 90m Long Box Beam 


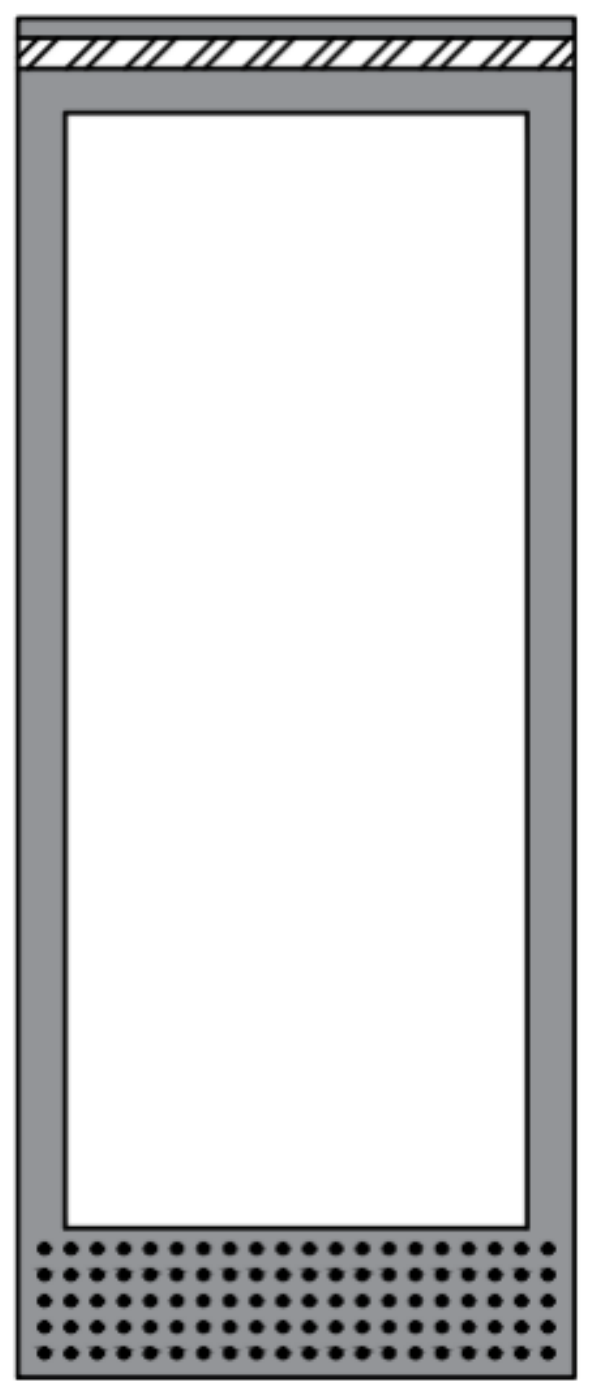

Figure $21 \mathrm{C} / \mathrm{s}$ of Transverse Post and Pre-Tensioning

\begin{tabular}{|l|l|}
\hline Moment & 0,60 \\
\hline Shear & 0,59 \\
\hline Transverse moment top flange (cracking) & 0,34 \\
\hline Transverse moment web (cracking) & 0,27 \\
\hline Deflection (traffic) & 0,21 \\
\hline Deflection (camber) & 0,49 \\
\hline Cracking & 0,48 \\
\hline Concrete fatigue & 0,03 \\
\hline Steel fatigue & 0,27 \\
\hline
\end{tabular}

Figure 22 Unity Check Performed on 90m Long Box Beam

\begin{tabular}{|l|r|r|r|r|r|}
\hline \multicolumn{7}{|c|}{ Beam and Bridge Properties } \\
\hline Span & 60 & 70 & 80 & 85 & 90 \\
\hline Concrete Class & $\mathrm{C} 170$ & $\mathrm{C} 170$ & $\mathrm{C} 170$ & $\mathrm{C} 170$ & $\mathrm{C} 170$ \\
\hline Slenderness ratio & 46,2 & 43,8 & 40,0 & 38,6 & 36,7 \\
\hline Height & 1300 & 1600 & 2000 & 2200 & 2450 \\
\hline Width & 1500 & 1500 & 1250 & 1000 & 1000 \\
\hline Top flange thickness & 170 & 170 & 170 & 170 & 170 \\
\hline Bottom flange thickness & 225 & 225 & 225 & 270 & 270 \\
\hline Web thickness & 90 & 85 & 85 & 85 & 85 \\
\hline Beam mass & 115,5 & 142,2 & 156,3 & 160,1 & 179,3 \\
\hline Total cross-section area & 7,55 & 7,97 & 9,20 & 11,09 & 11,73 \\
\hline Total amount of p-steel & 156000 & 174000 & 180000 & 225000 & 225000 \\
\hline \multicolumn{7}{|c|}{ Unity Checks } \\
\hline Moment & 0,66 & 0,58 & 0,64 & 0,57 & 0,60 \\
\hline Shear & 0,97 & 0,95 & 0,74 & 0,61 & 0,59 \\
\hline $\begin{array}{l}\text { Transverse moment top } \\
\text { flange (cracking) }\end{array}$ & 0,44 & 0,47 & 0,41 & 0,33 & 0,34 \\
\hline $\begin{array}{l}\text { Transverse moment } \\
\text { web (cracking) }\end{array}$ & 0,84 & 0,74 & 0,46 & 0,30 & 0,27 \\
\hline Deflection (traffic) & 0,34 & 0,31 & 0,23 & 0,22 & 0,21 \\
\hline Deflection (camber) & 0,16 & 0,17 & 0,28 & 0,34 & 0,49 \\
\hline Cracking & 0,46 & 0,43 & 0,50 & 0,45 & 0,48 \\
\hline Concrete fatigue & 0,28 & 0,42 & 0,04 & 0,15 & 0,03 \\
\hline Steel fatigue & 0,10 & 0,17 & 0,22 & 0,22 & 0,27 \\
\hline
\end{tabular}

Figure 23 Overall Comparison of Long Box Beam

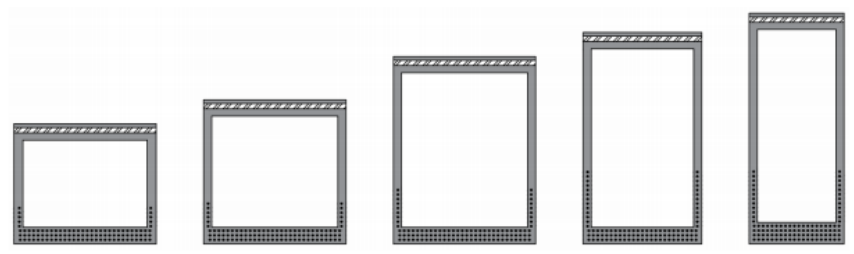

Figure 24 Diagram Representing Long Box Beam

\section{CONCLUSION}

A total of 5 models for UHPC package beam bridges with spans of $60 \mathrm{~m}, 80 \mathrm{~m}, 70 \mathrm{~m}, 85 \mathrm{~m}$ as well as $90 \mathrm{~m}$ were put together to help this theory. The styles are actually enhanced to minimalize material consumption and discover by far the slenderest as well as mild bridge attainable. This may be done with the next optimization strategies:

- Omit transverse reinforcement almost as possible

- Minimizing beam level until the optimum amount of prestress or maybe deformation capacity is actually reached

- Maximizing minimizing web and beam width thickness until shear capacity is actually reached

- Minimizing bottom flange thickness by using as a lot of strands as you can per level the layouts for spans of $60 \mathrm{~m}$ as well as $70 \mathrm{~m}$ may be enhanced with the technique above. The style for $80 \mathrm{~m}$ was constrained through the pounds cap of $170 \mathrm{t}$ for commuter routes by street. In order to keep this cap, the beam width is actually decreased. The breadth of $1500 \mathrm{~mm}$ would result in an exceedance, as a result the $80 \mathrm{~m}$ style has a breadth of $1250 \mathrm{~mm}$. For the exact same explanation, the $85 \mathrm{~m}$ beam has a reduced width of $1000 \mathrm{~mm}$. The style for $90 \mathrm{~m}$ couldn't be maintained below $170 \mathrm{t}$ without lessening the breadth to below $1000 \mathrm{~mm}$. Nevertheless, a 90m layout was even now made with $1000 \mathrm{~mm}$ breadth to exhibit the feasibility 


\section{International Journal of Engineering Applied Sciences and Technology, 2020 \\ Vol. 5, Issue 6, ISSN No. 2455-2143, Pages 19-26 \\ Published Online October 2020 in IJEAST (http://www.ijeast.com)}

and productivity the UHPC beam. Ultimately the optimized designs had been compared with current box beam strategies that make use of a lot of more traditional concrete sessions like C60. This comparison study proved that the UHPC beams hold the following benefits:

- More slender beams having a slenderness ratio of up to 46,2 may be made to satisfy strict slenderness needs as well as to reduce needed elevation height of this bridge. SKK-beams possess a slenderness ratio which range from thirty to thirtytwo.

- Lighter bridges with fat reductions up to thirty-six \% compared to SKK beam bridges could be made to greatly reduce loading on the bridge as well as improve the simplicity of transportation. Additionally, greater beams of $85 \mathrm{~m}$ may be made, while even now being in the position to carry these by road. Conclusions 114

- Wider beams of 1500 rather than $1200 \mathrm{~mm}$ may be made decreasing the entire mass of webs and cutting back on the number of beams which should be produced and sent.

- Beams which don't involve transverse reinforcement aside from transverse posttensioning could be made. This could bring down the needed quantity of labor and steel.

Besides the UHPC package beams with kinked hair strands in the webs an additional variant with straight locks in the webs is actually developed. This enables a reduction in the selection of strands in the bottom part flange and more locks in the net. As a result, a lot more slender and lighter beams could be turned around comparison to the UHPC package beams with kinked hair strands. The slenderness of the beams reaches up to forty-eight and the weight reduction gets to up to forty-one $\%$. This variant becomes just light that they are able to be moved by road while for $90 \mathrm{~m}$ longer beams. To further enhance this particular variant the strands in the strands and the web in the bottom part flange positioned below the net could be kinked. As an outcome, the sheer power grows. This's advantageous for smaller spans, permitting lighter bridges, by raising both beam width of minimizing web thickness. For large spans the beams can't be made any wider as a result of the 170t industry limit, therefore this approach just succeeds for shorter bridges. Nevertheless, in case these longer beams could be moved by water, subsequently the pounds limit no longer can be applied. In this particular situation these beams may be built wider and the method gets much more fascinating.

This very last most optimized variant called KSIW beams (Kinked Strands within Web) offer loads of potential programs since they're both slender and light very. Initially, they present a fit option for fresh bridges with spans which are way too long for typical package beam strategies, without having to create an intermediate pier or maybe switch to segmented or even cast in situ solutions. Next, they permit us to upgrade older bridges with a much stronger one without needing to change the current substructure. Both these apps have the benefit of lowering traffic hindrance. For the 2nd program it's also examined whether it's feasible to omit the current intermediate pier. Slenderness smart this's possible, since the KSIW beams only require almost no level for long spans. Nevertheless, they're not lightweight enough, to stop the reaction power at the abutment to remain the same with no intermediate pier.

Thus, the substructure should have adequate overcapacity, or maybe the substructure needs to be strengthened to create this possible. To conclude UHPC box beams are actually a fit option for both brand-new bridges and swapping old bridges, since they are able to result in much less traffic hindrance, because of their superb slenderness and lightness.

\section{REFERENCES}

[1] Yang Zhang, Chongyag Zhang, Yanping Zhu, Junhui Cao Xudong Shao (2020), An Experimental Study: various influence factor affecting interfacial Shear performance of UHPC - NSC

[2] Liang Rena, , Zhi Fangb , Kai Wanga (2019),Design and behavior of super-long span cable-stayed bridge with CFRP cables and UHPC members

[3] N.M Azmee, N Shafiq, (December 2018, Volume 9), Ultra-high-performance concrete: From fundamental to applications

[4] Chengqing Wu Jun Li Yu Su (March 2018, Edition 1), Development of Ultra-High-Performance Concrete against Blasts

[5] Kassel, Germany, (March 05 - 07, 2008), Ultra-HighPerformance Concrete: (UHPC); Proceedings of the Second International Symposium on Ultra High-Performance Concrete

[6] Hussam H Hussein, (2018), Analysis and Design of UltraHigh-Performance Concrete Shear Key for Precast Prestressed Concrete Adjacent Box Girder Bridges

[7] T.Ngo (2016) Application of UHPC in Long Span Bridge Design

[8] Fan Dingqiang,Tian Wenjing,Feng Dandian,Cheng Jiahao,(2018), Development and Applications of Ultra-high Performance Concrete in Bridge Engineering

[9] Xudong Shao, Lu Deng Junhui Cao ,(10 Innovative steel-UHPC composite bridge girders for long-span bridges

[10] Liang Ren,Zhi Fang,Kai Wang,(May 2019) Design and behavior of super-long span cable-stayed bridge with CFRP cables and UHPC members 
[11] Oguz Gunes, Seda Yesilmen, Burcu Gunes,and FranzJoseph Ulm,(31 ${ }^{\text {st }}$ May 2012), Use of UHPC in Bridge Structures: Material Modeling and Design

[12] Zachary Plevny, (Spring 2020), Applications of UltraHigh-Performance Concrete

[13] Sri Sritharan, (2015), Design of UHPC Structural Members: Lessons Learned and ASTM Test Requirements

[14] M. Qiu, X. Shao, H. Zhao, R. Pan, G. Chen, (2017), Super long-span longitudinal prestressed UHPC box-girder bridge

[15] Maher K. Tadros,(2009), Application of Ultra-High Performance Concrete to Bridge Girders 